\title{
Avaliação nas aulas de educação física: anos iniciais do ensino fundamental
}

\author{
Evaluation in physical education classes: early years of elementary school
}

Evaluación en clases de educación física: primeros años de la enseñanza primaria

\author{
Flora Silva Alves ${ }^{1}$; Hugo Paula Almeida da Rocha ${ }^{2}$ \\ Universidade Estadual Paulista “Júlio de Mesquita Filho", UNESP, Presidente Prudente-SP, Brasil
}

\begin{abstract}
RESUMO
O objetivo do estudo foi analisar as práticas avaliativas utilizadas por docentes de Educação Física de uma escola do primeiro segmento do Ensino Fundamental do Rio de Janeiro. Utilizamos dois questionários semiestruturados, o primeiro com perguntas relacionadas à formação acadêmica e profissional; e o segundo, com questões voltadas para avaliação nas aulas de Educação Física. Participaram da pesquisa cinco professores de Educação Física da escola do Rio de Janeiro. Os resultados mostraram que alguns professores não realizam avaliação nas aulas de Educação Física, justificando-se uma possível correlação com a falta de esclarecimento do que é avaliação. Por fim, supomos que avaliar ainda seja considerado sinônimo de atribuição de notas para alguns desses professores.
\end{abstract}

Palavras-chave: Avaliação. Educação Física Escolar. Ensino Fundamental.

\begin{abstract}
The aim of the study was to analyze the evaluative practices used by Physical Education teachers at a school in the first segment of Elementary Education in Rio de Janeiro. We used two semi-structured questionnaires, the first with questions related to academic and professional training; and the second, with questions aimed at evaluation in Physical Education classes. Five physical education teachers from the school in Rio de Janeiro participated in the research. The results showed that some teachers do not perform assessment in Physical Education classes, justifying a possible correlation with the lack of clarification of what assessment is. Finally, we assume that assessing is still considered a synonym for grading for some of these teachers.
\end{abstract}

Keywords: Evaluation. School Physical Education. Elementary School.

\section{RESUMEN}

El objetivo del estudio fue analizar las prácticas evaluativas utilizadas por los profesores de Educación Física en una escuela de enseñanza primaria en Río de Janeiro. Usamos dos guiones de entrevistas semiestructuradas, el primero con preguntas relacionadas a la formación académica y profesional y el segundo con preguntas sobre la evaluación en las clases de Educación Física. Hicimos la encuesta con cinco profesores de educación física de la escuela de Rio de Janeiro. Los resultados mostraron que algunos profesores no realizan evaluación en las clases de Educación Física justificando una posible correlación con la falta de aclaración de lo que es evaluación. Finalmente, asumimos que la evaluación todavía se considera sinónimo de calificación para algunos de estos profesores.

Palabras clave: Evaluación. Educación Física Escolar. Enseñanza Primaria.

\footnotetext{
${ }^{1}$ Mestre em Educação Física Escolar (PROEF/UNESP Presidente Prudente). E-mail: floraufrrj@hotmail.com. ORCID: http://orcid.org/0000-0003-3964-8608.

2 Docente do Programa de Mestrado Profissional em Educação Física em Rede Nacional (PROEF/UNESP Presidente Prudente). E-mail: hrocha.ufrj@gmail.com. ORCID: http://orcid.org/0000-0003-2237-1155.
} 


\section{INTRODUÇÃO}

As aulas de Educação Física segundo os Parâmetros Curriculares Nacionais (PCN) trabalham os conceitos, as atitudes e os procedimentos dos conteúdos na dimensão da cultura corporal, envolvendo esportes, jogos, lutas, ginásticas, atividades rítmicas e expressivas e conhecimentos sobre o corpo (BRASIL, 1997). O planejamento docente deve incluir premissas básicas como a meta que pretende que os estudantes atinjam, o método de ensino e procedimentos avaliativos. Entendemos avaliar como a coleta de dados que satisfaça aos objetivos traçados pelo docente, que tenham alinhamento com o projeto político pedagógico da escola e que contemplem a formação individual do estudante, orientando-o para uma melhor compreensão e conhecimento sobre sua função nos contextos da disciplina, da escola e da sociedade.

A educação física adentrou o espaço escolar ainda utilizando as referências dos métodos ginásticos, com origem no movimento militarista, na aptidão física e performance. Para Ghiraldeli Junior (1988) esta tendência está a serviço de uma hierarquização e elitização social. Seus valores fundamentais são competição e superação individual para uma sociedade moderna. Com isso, considerando os objetivos dessas correntes de ensino, os métodos avaliativos as acompanhavam, baseados nos princípios da aptidão física e da performance, sendo hoje considerados excludentes e autoritários para a Educação Física Escolar (EFE). Os procedimentos avaliativos levantavam informações sobre a competência dos estudantes para atingir determinadas metas de performance física, inspirados em protocolos atléticos.

A partir das abordagens de ensino que questionaram o estilo tradicional da EFE, muitos autores iniciaram um processo de incorporação de conceitos de outras áreas, como da cultura e da sociologia. Betti (1991) retrata uma visão holística sobre o corpo, sua função social e atribuições que essa disciplina deveria agregar no ambiente escolar. De acordo com Bracht (1999) a Educação Física passou a abranger as dimensões psicológicas, sociais, cognitivas e afetivas, enxergando os alunos como seres humanos integrais, capazes de desenvolver as manifestações da cultura corporal de movimentos. Soares et al. (1992) dizem que a avaliação nas aulas de Educação Física deve ir além dos dados numéricos, da seleção, classificação e da aptidão física. A avaliação deve abranger a realidade que o educando se encontra inserido, incluí-lo em seu contexto social e estar relacionada ao projeto político pedagógico da escola.

Segundo Zabala (1998), a avaliação deve envolver os conteúdos em três aspectos: atitudinais, conceituais e procedimentais. Sendo estes, respectivamente: o saber fazer, o saber pensar e o saber ser, conviver, de forma que não seja avaliado apenas o saber fazer ou o saber pensar; as atitudes em aula, a capacidade de resolução de conflitos, o respeito aos colegas, professores e a participação, também devem ser levados em consideração. $\mathrm{O}$ indivíduo precisa ser observado como um todo, sem que ocorra a fragmentação de seus saberes.

A partir da descrição sobre o conceito de avaliação para a EFE, observamos que ainda possa haver inconsistências entre o campo teórico e a prática docente. Nota-se que algumas redes de ensino fundamental, do primeiro segmento, não exigem rigorosamente a avaliação, deixando ao encargo do professor a decisão sobre como vai realizar esse procedimento com os estudantes. Isso causa constantes indagações do tipo: como ocorre a avaliação na EFE no primeiro segmento do ensino fundamental nessas redes de ensino? Portanto, o objetivo do estudo foi analisar as práticas avaliativas utilizadas por docentes de Educação Física de uma escola do primeiro segmento do ensino fundamental do Rio de Janeiro. 


\section{TRAJETÓRIA METODOLÓGICA}

Esta pesquisa é qualitativa descritiva (MORESI, 2003) e foi realizada em 2019. Os instrumentos de pesquisa foram dois questionários semiestruturados com questões abertas. O primeiro questionário com questões referentes à investigação sobre a formação acadêmica e experiência profissional do docente e o segundo questionário, com questões buscando analisar a forma de avaliação utilizada pelo professor em suas aulas de Educação Física. Cinco professores de Educação Física de uma escola do Rio de Janeiro, que atuam nos anos iniciais do ensino fundamental, participaram da pesquisa. A escolha da instituição e dos docentes foi por conveniência, considerando as ações da pesquisa. Houve uma reunião com a diretora da escola e os professores de Educação Física. Os objetivos da pesquisa foram explicados e as dúvidas sanadas. A diretora da unidade de ensino assinou a anuência e os professores receberam e assinaram um Termo de Consentimento Livre e Esclarecido. Também foram entregues aos participantes dois questionários semiestruturados, composto de questões abertas, para que pudessem responder em um momento oportuno e ter a garantia da privacidade. Após uma semana, os respondentes devolveram os questionários devidamente preenchidos.

Os dados foram tabulados e categorizados a partir da frequência de respostas dos professores, buscando responder aos objetivos da pesquisa. Nessa fase da investigação, foi realizada uma discussão entre o que os professores adotaram como métodos de avaliação e as propostas encontradas na literatura, referentes ao tema da avaliação na educação física.

\section{PERFIL DOS PARTICIPANTES DA PESQUISA}

O questionário 1 buscou identificar o perfil acadêmico e profissional dos professores pesquisados. O quadro a seguir mostra as respostas apresentadas pelos participantes da pesquisa.

Quadro 1: Perfil docente.

\begin{tabular}{|c|c|c|c|c|c|}
\hline Dados do Questionário & Prof. G & Prof. J & Prof. M & Prof. D & Prof. $\mathrm{H}$ \\
\hline Idade & 54 & 32 & 43 & 50 & 43 \\
\hline Instituição de Formação & Particular & Pública & Pública & Privada & Pública \\
\hline Ano de Formação & 89 & 2012 & 2001 & 1992 & 2001 \\
\hline $\begin{array}{l}\text { Curso de Pós-Graduação na } \\
\text { área }\end{array}$ & Lato Sensu & Lato Sensu & Não & Lato Sensu & Não \\
\hline $\begin{array}{l}\text { Tempo de exercício da profissão } \\
\text { de Professor de Educação Física }\end{array}$ & 30 anos & 5 anos & 17anos & 12 anos & 12anos \\
\hline Atuou na rede privada & Sim & Não & Sim & Não & Não \\
\hline $\begin{array}{l}\text { Tempo de atuação como } \\
\text { professor de Educação Física na } \\
\text { Prefeitura do Rio de Janeiro }\end{array}$ & 16 anos & 5 anos & 12 anos & 12 anos & 12 anos \\
\hline $\begin{array}{l}\text { Frequenta Congressos/ Cursos } \\
\text { de Atualização Profissional }\end{array}$ & Sim & Não & Não & Sim & Não \\
\hline $\begin{array}{lll}\text { Segmento de } & \text { Ensino } \\
\text { Fundamental que atua } & \end{array}$ & Primeiro & $\begin{array}{l}\text { Primeiro e } \\
\text { Segundo }\end{array}$ & $\begin{array}{l}\text { Primeiro e } \\
\text { Segundo }\end{array}$ & $\begin{array}{l}\text { Primeiro e } \\
\text { Segundo }\end{array}$ & Primeiro \\
\hline
\end{tabular}




\section{PROCEDIMENTOS DE ANÁLISE DOS DADOS}

Em relação ao questionário 2, com 10 questões abertas, a formação das categorias foi realizada de acordo com Bardin (2010), após a seleção do material e a leitura exploratória, a exploração ocorreu através da codificação, que se concretizou em função da repetição das palavras. Foram executadas unidades de registro, de acordo com a observação dos resultados, desta forma realizou-se a categorização progressiva.

Desta forma foram destacadas três categorias, baseadas nas questões presentes no questionário 2. São elas: 1- Concepção de avaliação, 2- Métodos avaliativos e 3Instrumentos avaliativos. Para preservar o anonimato dos participantes, optou-se por nominar os sujeitos da pesquisa com a primeira letra do nome, por exemplo: Maria letra "M". Como foram cinco os sujeitos, utilizamos cinco letras para representá-los.

\section{RESULTADOS E DISCUSSÃo}

\section{1- CONCEPÇÃO DE AVALIAÇÃO}

Os aspectos da concepção de avaliação foram apresentados de forma similar pelos professores. Eles consideraram que a avaliação seria um instrumento que possibilitaria compreender o nível de aprendizagem dos estudantes. Apenas um professor se posicionou em oposição, associando a avaliação à aplicação de notas e conceitos:

Sou contra a avaliação no que diz respeito a atribuir notas e conceitos (Professor G).

A maior parte do grupo identificou a avaliação como o instrumento que os levaria a levantar dados e o professor $\mathrm{G}$ associou o processo avaliativo da aprendizagem com a sistematização de notas ou conceitos aos estudantes. Observando os PCN (BRASIL, 1997), a avaliação transcende a visão tradicional, de limitar os alunos por meio de notas e conceitos, ela é parte integrante do processo educacional, sendo atuações contínuas e sistemáticas à interpretação do conhecimento constituído pelo aluno, definindo prioridades e localizando aspectos que demandam maior apoio ao aprendizado do estudante.

Comparando a resposta do professor $\mathrm{G}$ com o seu perfil, apesar de ter respondido que está em constante atualização em Congressos Científicos, confundiu a avaliação com atribuição de notas e conceitos, no entanto, os documentos norteadores e a literatura atual da área nos remetem a uma visão ampla da avaliação nas aulas de Educação Física. Tal visão, pode estar associada ao período que esse professor cursou a faculdade de Educação Física, como foi exposto no quadro 1. O período de formação desse educador se deu num momento histórico em que, segundo Depresbiteris (1989), a avaliação do processo ensino-aprendizagem estava associada à aplicação de testes, o que a tornava um processo instrumental.

O professor $\mathbf{J}$ demonstrou reconhecer a importância da avaliação:

É importante e fundamental para o professor saber se está alcançando o objetivo e o aluno deve ter um feedback desta avaliação para saber em que precisa melhorar e evoluir (Professor J).

A avaliação deve ir além, ser abrangente e sobrepor ao autoritarismo imposto pela sociedade, "[...] diagnosticar qual a posição do aluno em determinado momento em relação aos objetivos fixados e por que tem ou não dificuldades de progredir" (SOUSA, 
1993, p. 148). A avaliação serve como forma de repensar o planejamento, rever os conteúdos, metodologia do ensino e a prática pedagógica.

Segundo Luckesi (2005), a avaliação não deve ser um ato impensado, mas algo que valorize o aprendizado dos estudantes, observando-os, detectando as dificuldades e transformando-as no caminho do aprendizado, além de permitir ao professor se auto avaliar, mudando suas estratégias e transformando suas metodologias. A avaliação não se aplica apenas ao estudante, mas também ao desempenho do professor e às suas metodologias de ensino, pois se o estudante não aprendeu, pode ser que o professor não tenha utilizado de uma metodologia que fizesse com que os estudantes entendessem o que foi ensinado. Portanto, é necessário que o professor tenha embasamento teórico, conheça as diversas metodologias e renove, transforme o ato de ensinar. De acordo com Luckesi (2005, p. 172), "[...] a avaliação é um ato amoroso, acolhedor e inclusivo, ajuizando a sua qualidade, dando lhe suporte para mudanças".

Segundo o Professor M, a Secretaria de Educação demonstra não existir nenhum tipo de exigência em relação à avaliação nas aulas de Educação Física:

Considero importante a avaliação na disciplina de Educação Física, porém pouco explorada na Rede [de ensino]. Os professores do primeiro segmento não são estimulados a realizar nenhum tipo de avaliação (Professor M).

O Professor M, que atua na rede de ensino do Rio de Janeiro há 12 anos, apesar de ter julgado importante a avaliação nas aulas de Educação Física, relatou que a entidade gestora não faz imposição de registros obrigatórios em diários de classe ou registros formais. Logo, ele não realiza avaliação em suas aulas, justificando sua decisão ao fato de não receber estímulos da rede.

A pouca atenção que vem sendo dada à aplicação dos conhecimentos disponíveis no campo da avaliação, a qual o Professor $M$ faz referência, está intrinsecamente relacionada à desvalorização da disciplina na escola. Observamos que o Professor $\mathbf{M}$ não frequenta Congressos e não cursou pós-graduação. De acordo com Oelke et al. (2010), a formação permanente deve servir como forma de aperfeiçoamento e deve estar vinculada à visão que os professores têm de si mesmos e do papel social da educação física.

O professor deve assumir de maneira consciente sua função de educador e profissional da educação, conscientizando-se e incentivando a escola, família e sociedade, determinando a função da Educação Física na Escola, contribuindo de maneira a evidenciar a importância do componente.

A defasagem neste aspecto reflete a falta de compromisso e de um planejamento eficaz, desvalorizando todo o conjunto.

Os outros três professores tiveram respostas parecidas quanto à relevância da avaliação:

\footnotetext{
Acho importante assim como nos demais componentes do currículo (Professor D).

Considero importante para levar em consideração os conhecimentos teóricos e práticos dos alunos (Professor $\mathrm{H}$ ).

É importante e fundamental para o professor saber se está alcançando o objetivo e o aluno deve ter um feedback desta avaliação para saber em que precisa melhorar e evoluir (Professor J).
}

O Professor D generalizou a importância da avaliação em todas as disciplinas, mostrando uma visão abrangente sobre avaliação, além dos limites da Educação Física. $\mathrm{O}$ professor $\mathrm{H}$ citou a importância de considerar os conhecimentos discentes no processo avaliativo, algo que precede a intervenção do docente. E o Professor J 
respondeu que é importante que os alunos tenham acesso aos resultados das suas avaliações.

Ziliotto et al. (2015) concluem que há um claro descompasso entre o que se desenvolveu no plano teórico e a prática cotidiana nas escolas. Para o enfrentamento deste cenário é necessário que o professor tenha um espírito investigativo, mobilize matrizes teóricas da área e proponha estratégias para resolução de seus problemas.

As aulas de Educação Física serem ministradas sem o devido planejamento e projeção de objetivos, acabam por perder a sua real importância na vida dos estudantes, além de transparecer para os membros da comunidade escolar que o professor não se importa com a estruturação das ações, manchando a imagem da disciplina.

Para Caldeira (2000):

\begin{abstract}
A avaliação escolar é um meio e não um fim em si mesma; está delimitada por uma determinada teoria e por uma determinada prática pedagógica. Ela não ocorre num vazio conceitual, mas está dimensionada por um modelo teórico de sociedade, de homem, de educação e, consequentemente, de ensino e de aprendizagem, expresso na teoria e na prática pedagógica (p. 122).
\end{abstract}

De acordo com a Lei Federal no 9.394/96 (Lei de Diretrizes e Bases da Educação Nacional), artigo 24, inciso V, alínea a, é preciso considerar “[...] a avaliação contínua e cumulativa do desempenho do aluno, com prevalência dos aspectos qualitativos sobre os quantitativos, e dos resultados ao longo do período sobre eventuais provas finais" (BRASIL, 1996).

É de suma importância destacar que essa concepção referenciada pela legislação exige do professor um posicionamento crítico no processo educativo, na medida em que o comportamento do aluno deve ser interpretado, julgado e analisado. Desta maneira, a medida decisiva para a promoção do aluno não deve ser obtida de um instrumento único.

\title{
Conforme preconiza Hoffmann (1996):
}

[...] a avaliação, enquanto relação dialógica vai conceber o conhecimento como apropriação do saber pelo aluno e pelo professor, como ação-reflexãoação que se passa na sala de aula em direção a um saber aprimorado, enriquecido, carregado de significados, de compreensão (HOFFMANN, 1996, p. 148).

A avaliação deve permitir ao professor refletir suas atitudes e ações e ao estudante deve oferecer informações sobre seu desenvolvimento nos diversos aspectos. A avaliação deve ser um processo contínuo e que atravessa toda a prática educativa, contando com a participação de professores, alunos e equipe pedagógica (DARIDO; RANGEL, 2011). Avaliar deve abranger o processo de ensino e aprendizagem, e ser acolhedora (PERRENOUD, 1999; CARVALHO; UYTDENBROEK, 2000; LUCKESI, 2011).

\section{2- MÉTODOS AVALIATIVOS}

Sobre os métodos avaliativos, os respondentes afirmaram que não utilizam metodologias de avaliação. Percebe-se então, uma controvérsia, visto que na categoria "Concepção de avaliação", os cinco professores consideram a avaliação importante para o processo de ensino, ou seja, consideram importante, mas não executam em sua disciplina: 
Não realizo no primeiro segmento, somente no segundo segmento em outra escola municipal que trabalho (Professor D).

É possível perceber em suas respostas que há uma falta de esclarecimento do que seriam métodos avaliativos, pois ao responder que não realizam porque não atribuem notas, entendemos que estão erradamente relacionando métodos avaliativos aos instrumentos avaliativos.

Além disso, o Professor $\mathrm{H}$ também associou avaliar ao ato de quantificar o processo avaliativo. Não se trata de uma afirmação, porém a justificativa dessa resposta pode estar atrelada ao fato deste professor estar formado há quase vinte anos e não buscar atualização em cursos e congressos.

Segundo Soares et al. (1992), por vezes a avaliação não tem êxito no processo de aprendizagem nas aulas de Educação Física porque falta, em alguns professores, o discernimento do verdadeiro significado da avaliação, fazendo com que busquem conhecimento a respeito do tema nas ideologias tradicionais, que não são suficientes para explicar tamanho fenômeno educativo.

De acordo com Betti e Zuliani (2002), os métodos avaliativos em educação física têm as suas singularidades, mas concordam que devem corroborar e problematizar a ação pedagógica, e não somente atribuir nota ou conceito ao educando.

\footnotetext{
Avaliar é muito importante para o processo de ensino, orientando as ações do professor e auxiliando o aluno a identificar suas dificuldades a fim de melhorá-las (Professor J).

É essencial detectar as dificuldades e os progressos em todas as esferas que a Educação Física, tão rica, nos possibilita. É preciso estar atento às possibilidades dos alunos (Professor G).
}

Apesar de não especificar qual método de avaliação faz uso, o Professor G em sua resposta nos levou a entender que faz uso da observação e a considera como fator fundamental e constante nas aulas, a fim de que possa efetuar uma avaliação abrangente das aprendizagens. O Professor J falou da importância do ato de avaliar, porém também não especificou qual método utiliza em sua prática pedagógica.

Gimeno Sacristán e Pérez Gómez (2000) afirmam que os métodos avaliativos adotados pelo professor são, em grande parte, dos indícios selecionados pelo professor como relevantes para, por meio deles, chegar a um julgamento. Esta ação mediadora, que transforma as informações disponíveis (normalmente condutas ou trabalho materialmente observável) em conceito bimestral, é um processo cognitivo-profissional particular de cada professor, cujos requisitos são de difícil explicação, porque envolvem crenças e valores.

A falta de sistematização dos métodos de avaliação na disciplina de Educação Física tem levado os professores a não avaliar seus alunos da forma que deveriam fazer. Conforme Mattos e Neira (2000), a avaliação nas aulas de Educação Física tem correspondido a exigências das instituições de ensino, considerando a presença nas aulas, o bom comportamento. Algumas vezes os professores estão deixando de avaliar, como vimos nas respostas do questionário. Essas atitudes levam à desconsideração da reflexão a respeito do papel que a avaliação assume enquanto elemento constitutivo de um projeto pedagógico.

Mattos e Neira (2000) sugerem que os educandos e educadores discutam os critérios a serem adotados, contribuindo para o entendimento do planejamento anual e permitindo que os alunos opinem e participem da escolha dos métodos avaliativos.

A avaliação deve permear todo o processo ensino-aprendizagem, de modo que seja contínua e diagnóstica, possibilitando aos alunos condições para refletir sobre suas 
dificuldades e possibilidades. E aos professores, analisar sua metodologia de ensino, fornecendo elementos para adequar e ajustar melhores formas de aprendizagem.

Bloom et al. (1983) falam da existência de três métodos de avaliação: a diagnóstica, a formativa e a somativa. A diagnóstica está ligada à identificação de capacidades e/ou ao déficit que o indivíduo traz consigo no início do processo. $\mathrm{Na}$ formativa, a intenção é dar pistas sobre o posicionamento do aluno durante a aprendizagem e sugerir soluções a partir da identificação das possíveis dificuldades, a fim de alcançar o objetivo. Por fim, a somativa tem por objetivo a observação dos resultados alcançados ao final de uma intervenção pedagógica.

\section{3- INSTRUMENTOS AVALIATIVOS}

Os professores $\mathrm{D}, \mathrm{H}$ e $\mathrm{M}$ responderam que não utilizam instrumentos avaliativos, pois não realizam a avaliação, assim como foi exposto nas respostas referentes à categoria anterior.

Nenhum (Professor M e Professor H).

Não utilizo (Professor D).

Apesar de concordarem que avaliar é importante, se contradizem pelo fato de não utilizarem instrumentos e não registrarem a avaliação dos seus alunos. Mesmo não informando de maneira específica qual a metodologia de avaliação utilizam, quando questionados sobre quais os instrumentos utilizados para avaliar seus alunos, os professores $\mathrm{G}$ e $\mathrm{J}$ deram a seguinte resposta:

Utilizo relatórios, fichas de observação individual e registros (Professor G). Registro em meu caderno de anotações os casos mais críticos e que precisam de mais atenção, só para ter guardado comigo, a fim de me orientar (Professor J).

Todos os professores participantes deste estudo responderam que não preenchem fichas, diários de classe ou qualquer outra forma de registro formal para lançarem notas na disciplina de Educação Física, na escola de primeiro segmento envolvida no estudo. Quando perguntados se transformam em notas/conceitos os resultados da avaliação na disciplina, todos os professores afirmaram que não.

Os professores $\mathrm{G}$ e $\mathrm{J}$ que relataram utilizar anotações pessoais para registrar sua avaliação, mesmo que a entidade gestora e a direção da escola não façam nenhum tipo de exigência destes registros. No entanto, os professores não responderam como realizam o feedback referente ao desenvolvimento afetivo, procedimental e cognitivo dos estudantes.

Embora o Professor G tenha trinta anos de atuação como Professor de Educação Física e o Professor $\mathbf{J}$ tenha cinco anos, ambos cursaram pós-graduação na área, frequentam cursos e congressos científicos, buscando atualização profissional. Apesar da diferença de tempo de experiência, ambos responderam que utilizam o mesmo instrumento avaliativo, as anotações e registros informais.

$\mathrm{O}$ professor $\mathrm{G}$ relata como fornece aos alunos os resultados obtidos das avaliações:

Analiso, faço o acompanhamento através de novos registros, definindo critérios para planejar e criar atividades que possam gerar avanços na aprendizagem e na formação dos alunos (Professor G).

Segundo as respostas o Professor G, este guarda para si as anotações da avaliação dos seus alunos, não compartilhando as informações com os estudantes, direção e 
Conselho de Classe, utilizando essas informações apenas como base para nortear suas próximas ações. Para Smole (citada por DARIDO, 2012) os instrumentos mais utilizados são: observação e registro; análise de registro dos alunos; provas e análise de erros e autoavaliação. A autora sugere também a formação de um portfólio do aluno com trabalhos, projetos, reflexões, elaborados ao longo do tempo para gerar um diálogo, uma espécie de feedback do desenvolvimento dos discentes.

O Professor J relata o que faz com suas anotações:

Converso com os alunos ao final do bimestre a respeito da evolução deles e o que precisam melhorar nos aspectos procedimentais, atitudinais e conceituais (Professor J).

O Professor $\mathbf{J}$ respondeu dar um feedback da turma ao final do processo avaliativo, mostrando não conseguir identificar qual o método avaliativo utiliza em suas aulas. O docente também respondeu informar, ao final do bimestre, um posicionamento geral da turma, como se a avaliação fosse algo homogêneo aos educandos, aparentando não respeitar as individualidades dos alunos no processo de aprendizagem, pois o feedback é geral e não dos alunos em suas particularidades.

Darido e Rangel (2011) propõem que a avaliação em Educação Física permeie o caminho de observar, analisar e conceituar os principais elementos que englobam a totalidade da conduta humana. Logo, a avaliação deve buscar a aquisição de competências, habilidades, conhecimentos e atitudes dos alunos, abrangendo os conhecimentos, as habilidades motoras e as atitudes (respeito e valores), observando a perspicácia que o aluno consegue sistematizar os conhecimentos referentes à cultura corporal de diversas formas de linguagens (corporal, escrita e falada).

Darido e Rangel (2011) dizem que é de suma importância a utilização de diversos instrumentos, buscando a melhor forma para alcançar os objetivos que se pretende no ato de ensinar. Para as autoras a problemática não está nos instrumentos que serão utilizados e sim no que se pretende. Como por exemplo, para avaliação das habilidades e atitudes, é possível que se utilize provas, trabalhos, seminários, vídeos, observações sistemáticas, fichas, entre outros. O que realmente importa para autora é o rumo da avaliação, esta deve servir como um contínuo diagnóstico do processo de ensino e ter utilidade para toda comunidade escolar.

\section{CONSIDERAÇÕES FINAIS}

O objetivo do estudo foi analisar as práticas avaliativas utilizadas por docentes de Educação Física de uma escola do primeiro segmento do ensino fundamental do Rio de Janeiro. Entendemos que essa meta nos levou a um viés de resposta, porque poderia haver uma tendência de os docentes responderem algo relacionado a um ideal normativo. Mesmo essa possibilidade sendo verdadeira, o estudo levantou questões interessantes que merecem um tratamento ampliado sobre a avaliação na EFE do Rio de Janeiro, nos anos iniciais do ensino Fundamental.

Observamos que os docentes, apesar de julgarem o processo avaliativo como sendo relevante para o desenvolvimento e aprendizado dos estudantes, houve uma controvérsia entre tais declarações e o modo como eles relataram suas práticas avaliativas. As hipóteses que pudemos destacar para a possível desmotivação dos professores para a realização de algum tipo de avaliação nos anos iniciais do ensino fundamental dessa escola do Rio de Janeiro são: a falta de uma cobrança por parte da entidade gestora da rede de ensino e até mesmo da própria direção da instituição sobre o 
registro sistematizado do processo avaliativo; e um possível desconhecimento ou confusão sobre os conceitos de avaliação, método avaliativo e instrumentos de avaliação.

Nosso estudo teve um caráter qualitativo descritivo e não pretende fazer qualquer tipo de generalização, todavia, podemos notar que ele trouxe questões que podem ser objeto de novas intervenções de pesquisa que busquem entender se as hipóteses lançadas aqui são verificadas em outros contextos em que a EFE atenda ao primeiro segmento do ensino fundamental. É importante mencionar que a avaliação da aprendizagem é um elemento importante do processo de ensino e, isso se justifica, pois através dela é possível acompanhar a eficácia do ensino do professor e o desempenho do estudante, compreender os conteúdos e analisar o desenvolvimento e o aprendizado.

Por fim, torna-se importante destacar que avaliar não é cumprir exigências burocráticas, mas um processo de construção de conhecimento.

\section{REFERÊNCIAS}

BARDIN, L. Análise de conteúdo. 4. ed. Lisboa: Edições70, 2010.

BETTI, M. Educação física e sociedade. São Paulo: Editora Movimento, 1991.

BETTI, M.; ZULIANI, L. R. Educação física escolar: uma proposta de diretrizes pedagógicas. Revista Mackenzie de Educação Física e Esporte, v. 01, n. 01, 2002.

BLOOM, B.; ENGELHART, M. D.; FURST, E. J.; HILL, W. H.; KRATHWOHL, D. R. Taxonomia dos objetivos educacionais: domínio cognitivo. Porto Alegre: Globo, 1983.

BRACHT, V. A constituição das teorias pedagógicas da educação física. Caderno CEDES, v.19, n. 48, p. $69-88,1999$.

BRASIL. Secretaria de Educação Fundamental. Parâmetros curriculares nacionais: primeiros e segundos ciclos: Educação Física. Brasília: MEC/SEF, 1997.

BRASIL. Lei $n^{0} 9.394$ de 20 de dezembro de 1996. Estabelece as diretrizes e bases da educação nacional. Brasília: MEC, 1996.

CALDEIRA, A. M. S. Avaliação e processo de ensino aprendizagem. Presença Pedagógica, Belo Horizonte, v. 3, p. 122, set./out. 2000.

CARVALHO, M. H.; UYTDENBROEK, X. (org.). Avaliar com os pés no chão: reconstruindo a prática pedagógica no ensino fundamental. Pernambuco: UFPE, 2000.

DARIDO, S. C.; RANGEL, I. C. A. Educação física na escola: implicações para a prática pedagógica. 2. ed. Rio de Janeiro: Guanabara Koogan, 2011.

DARIDO, S. C. A avaliação da educação física na escola. In: UNESP. Prograd. Caderno de formação: formação de professores - didática dos conteúdos, v. 6. São Paulo: Cultura Acadêmica, 2012. p. 127-140. Disponível em: https://acervodigital.unesp.br/bitstream/123456789/41556/1/Caderno_blc2_vol6.pdf. Acesso em: 08 jun. 2020.

DEPRESBITERIS, L. O desafio da avaliação da aprendizagem: dos fundamentos a uma proposta inovadora. São Paulo: EPU, 1989.

GHIRALDELLI JUNIOR P. Educação física progressista: a pedagogia crítico-social dos conteúdos e a educação física brasileira. São Paulo: Loyola. 1988.

GIMENO-SACRISTÁN, J.G.; PÉREZ-GÓMEZ, A. I. Compreender e transformar o ensino. 4. ed. Porto Alegre: Artmed, 2000. 
HOFFMANN, J. Avaliação mediadora uma prática em construção da pré-escola a universidade. Porto Alegre: Mediação, 1996.

LUCKESI, C. C. Avaliação da aprendizagem: componente do ato pedagógico. São Paulo: Cortez, 2011.

LUCKESI. Avaliação da aprendizagem escolar: estudos e proposições. 17. ed. São Paulo: Cortez, 2005.

MATTOS, M. G.; NEIRA, M. G. Educação física na adolescência: construindo o conhecimento na escola. São Paulo: Phorte, 2000.

MORESI, E. (org.). Metodologia da pesquisa. Brasília: UCB, mar. 2003.

OELKE, S. A.; RAITER, G.; MONTAGNOLI, D. A formação do profissional da educação física: algumas perspectivas. In: CONGRESSO SULBRASILEIRO DE CIÊNCIAS DO ESPORTE, 5., 2010, Itajaí-SC. Anais [...]. Itajaí-SC, 2010. p. $\quad 1-10 . \quad$ Disponível em: http://congressos.cbce.org.br/index.php/sulbrasileiro/vcsbce/paper/view/1909/1104. Acesso em: 08 jun. 2020.

PERRENOUD, P. Avaliação: da excelência à regulação das aprendizagens. Porto Alegre: Artmed, 1999.

SOARES, C. L.; TAFFAREL, C. N. Z.; VARJAL, E.; CASTELLANI FILHO, L.; ESCOBAR, M. O., BRACHT, V. Metodologia do ensino da educação física. São Paulo: Cortez, 1992.

SOUSA, C. P. Avaliação do rendimento escolar. 2. ed. Campinas: Papirus, 1993.

ZABALA, A. A prática educativa: como ensinar. Porto Alegre: Artmed, 1998.

ZILIOTTO, D. S.; SILVA, R. O.; LOURENÇO, S.; HAUTH, L. O.; FERREIRA, A. L. P.; GURSKI, L. L. Educação física escolar e educação crítica: refletindo necessidades, fomentando a pesquisa. Cadernos da Escola de Educação e Humanidades, Curitiba, v. 1 n. 10, p. 44-59, 2015.

Recebido em: 14 jul. 2020.

Aprovado em: 29 ago. 2020. 